\title{
Radial Dilation of Nephrostomy Balloons: A Comparative Analysis
}

\author{
Kari Hendlin, Manoj Monga
}

Departments of Urologic Surgery, VAHCS Minneapolis, University of Minnesota, Minneapolis, Minnesota, USA

\begin{abstract}
Purpose: The dynamics of percutaneous balloon expansion may differ with increasing extrinsic compressive forces and increasing inflation pressures. This study compares the ability of percutaneous balloons to expand under different radial constrictive forces.

Materials and Methods: Three 30F nephrostomy balloons were tested: Bard X-Force ${ }^{\mathrm{TM}}$, Boston Scientific Microvasive Amplatz Tractmaster ${ }^{\mathrm{TM}}$, and Cook Ultraxx ${ }^{\mathrm{TM}}$. With a super stiff guidewire in place, the balloon tip was secured by elevated vice grips on either side of the balloon. A string was wrapped around the balloon center once, and incremental increases in load were added $(2 \mathrm{~g}, 42 \mathrm{~g}, 82 \mathrm{~g}$, and $122 \mathrm{~g})$ to represent increasing extrinsic compression. The balloon was inflated with a contrast agent and circumference changes were measured at increments of 4 ATM, 10 ATM, and burst pressure. Balloons were tested in triplicate for each load.

Results: All balloons were unable to reach $90 \%$ of their expected diameter with larger constrictive loads (122g) at low (4 ATM) and nominal (10 ATM) inflation pressures. Only the Bard and Cook balloons reached at least $90 \%$ of the expected diameter with a coefficient of variance (CV) less than $10 \%$ at burst pressure under the larger constrictive load (122g), $94.3 \% \pm 6.7 \%, \mathrm{CV} 7.1 \%$ and $96.3 \% \pm 2.9 \%, \mathrm{CV} 3.0 \%$ respectively. All balloons performed well under low constriction forces and reached at least $80 \%$ of the expected diameter by 10 ATM under all constrictive loads.

Conclusions: The Bard X-Force and Cook Ultraxx percutaneous nephrostomy balloons achieved the most reliable radial dilation against large constrictive forces simulating fascial or retroperitoneal scar tissue.
\end{abstract}

Key words: balloon dilation; percutaneous nephrolithotomy; renal calculi

Int Braz J Urol. 2008; 34: 546-54

\section{INTRODUCTION}

Percutaneous renal access is an important component of many complex procedures including stone extraction, antegrade endopyelotomy, and resection of transitional cell carcinoma of the upper urinary tract. The choice of nephrostomy tract dilation technique is significant in minimizing the risk of complications such as blood loss and perforation of the collecting system. Approaches to percutaneous nephrostomy tract dilation have included serially introduced, progressive fascial dilators, Amplatz dilator sets, metal coaxial dilators and high pressure balloons. Balloon systems have recently become the instrument of choice as they allow for one-step dilation, minimized total operative and fluoroscopic time, and reduced risk of hemorrhage in comparison to other methods of tract dilation (1-3). It has been proposed that the lateral compressive forces produced by the balloons are less traumatic and thereby minimize complications in comparison to the angular shearing forces exerted by successive dilation methods $(1,4)$.

The dynamics of percutaneous balloon expansion may differ with increasing extrinsic compressive forces and increasing inflation pressures. This study 
Table 1 - Percutaneous nephrostomy balloons tested.

\begin{tabular}{|c|c|c|c|}
\hline Balloon & Inflated Diameter (mm) & Length $(\mathrm{cm})$ & Burst Pressure (ATM) \\
\hline Bard X-Force ${ }^{\mathrm{TM}}$ & 10 & 15 & 30 \\
\hline Cook Ultraxx ${ }^{\mathrm{TM}}$ & 10 & 15 & 20 \\
\hline BSM TractMaster ${ }^{\mathrm{TM}}$ & 10 & 12 & 17 \\
\hline
\end{tabular}

compares the ability of several percutaneous balloons to expand under different radial constrictive forces.

\section{MATERIALS AND METHODS}

Three 30 Fr nephrostomy balloons were tested: Bard X-Force ${ }^{\mathrm{TM}}$ (Bard, Covington, GA) Boston Scientific Microvasive Amplatz Tractmaster ${ }^{\mathrm{TM}}$ (Boston Scientific, Natick, MA), and Cook Ultraxx ${ }^{\mathrm{TM}}$ (Cook Urological, Spencer, IN) (Table-1). Testing methods used were the same as those used to test commercially available ureteral balloons (5). The initial circumference, prior to any inflation, was measured at the balloon center. With a super stiff guidewire in place, the balloon tip was secured by elevated vise grips on either side of the balloon (Figure-1). A small plastic bag for adding radial load was attached to a string, which was wrapped around the balloon once

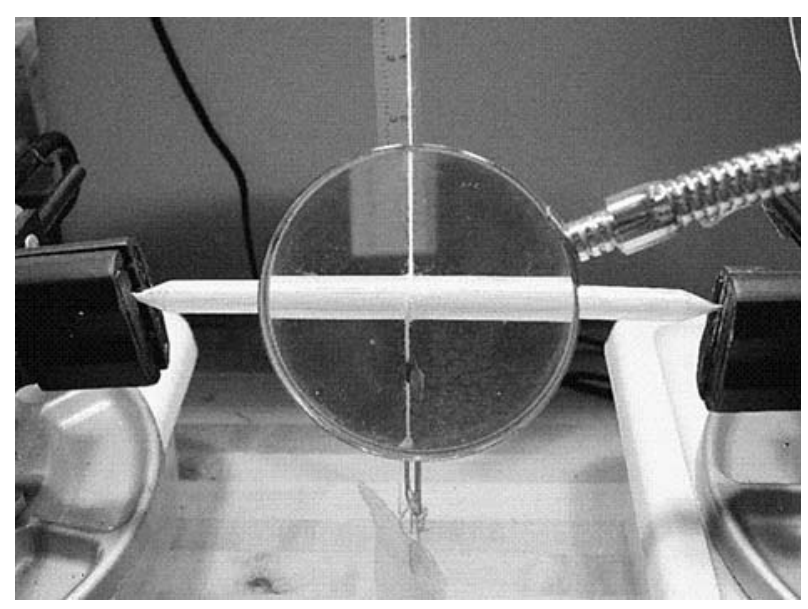

Figure 1-Test set-up. and then secured so that the bag was hanging between the vice grips and centered beneath the balloon. A ruler measuring $1 / 100^{\text {th }}$ of an inch was secured vertically to the ledge directly behind the center of the balloon. Contrast solution was mixed in a 1:1 ratio with water. A Cook inflation device (Patent no. 5,860,955) was used to inject contrast solution into the balloon inflation port. Pressure was increased and the change in balloon circumference was recorded at pressures of 4 ATM, 10 ATM and burst pressure. Balloons were tested three times consecutively for each radial load of $2 \mathrm{~g}, 42 \mathrm{~g}, 82 \mathrm{~g}$, and $122 \mathrm{~g}$. These loads were selected to evaluate balloon performance through a range of simulated constrictive forces. These constrictive forces have previously been demonstrated to be effective at eliciting differences in balloon performance for ureteral balloons (5). Statistical comparisons were performed using 95\% confidence intervals, ANOVA, and one-sample t-tests compared to $100 \%$ inflation diameter per manufacturer. A p value $<0.05$ was considered statistically significant. Results were reported as coefficient of variance (\%), mean (\%) \pm standard deviation $(\%)$.

\section{RESULTS}

All balloons were unable to reach $90 \%$ of their expected diameter with larger constrictive loads $(122 \mathrm{~g})$ at low (4 ATM) and nominal (10 ATM) inflation pressures (Figure-2 and Figure-3). Only the Bard $\mathrm{X}$-Force ${ }^{\mathrm{TM}}$ and Cook Ultraxx ${ }^{\mathrm{TM}}$ balloons reached at least $90 \%$ of the expected diameter with a coefficient of variance $(\mathrm{CV})$ less than $10 \%$ at burst pressure under the larger constrictive load (122g), $(94.3 \% \pm 6.7 \%$, CV $7.1 \%$ and $96.3 \% \% \pm 2.9 \%$, CV $3.0 \%$ respectively) (Figure-4) (Table-2). 


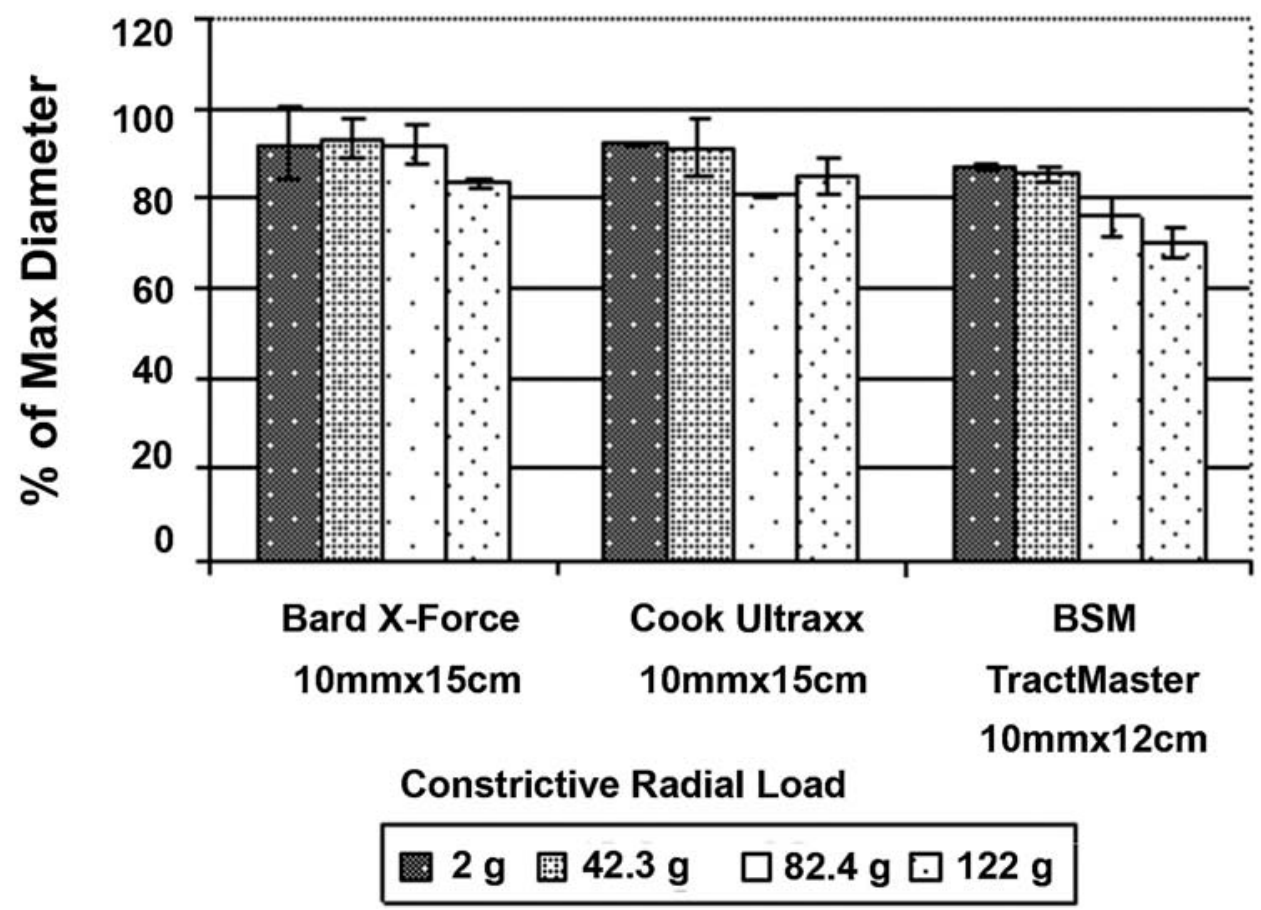

Figure 2 - Balloon dilation at 4 ATM.

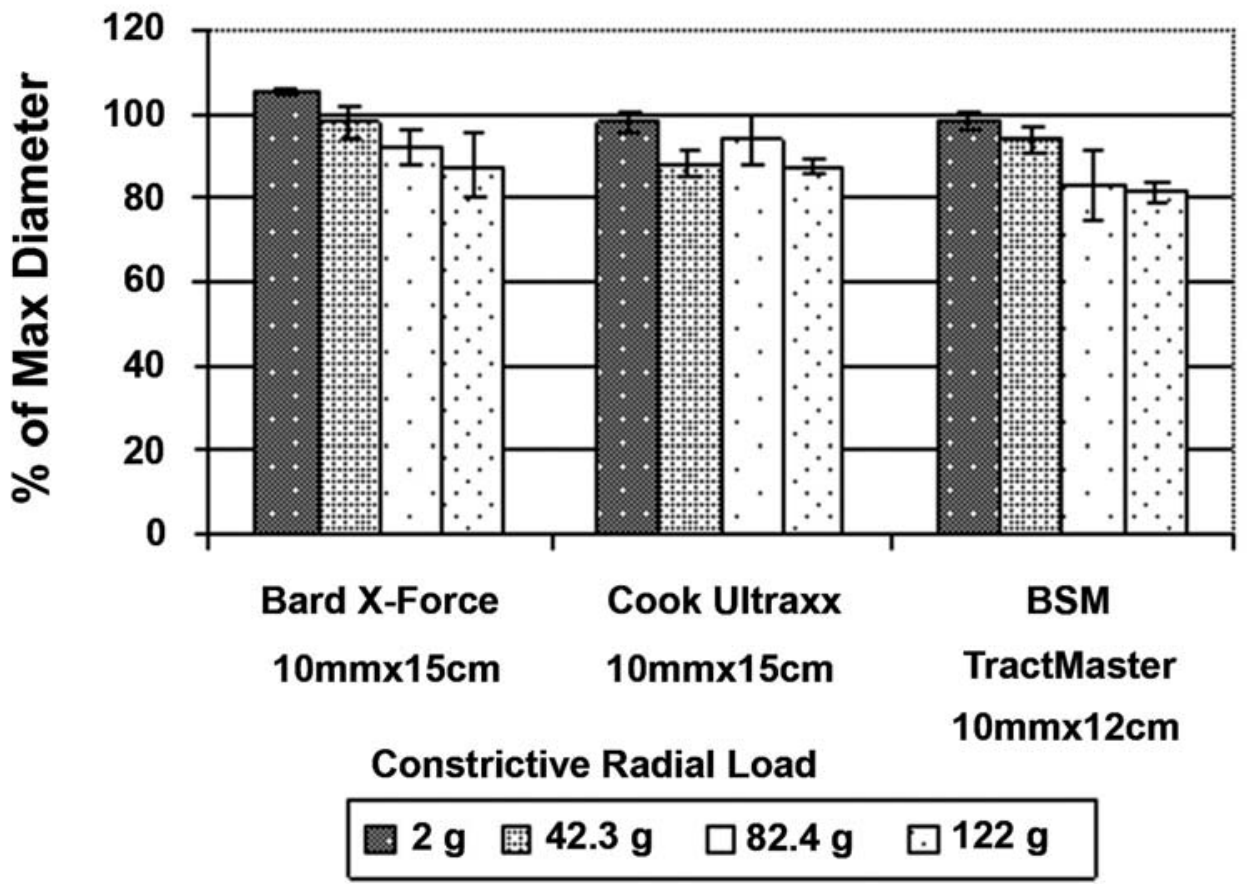

Figure 3 - Balloon dilation at 10 ATM. 


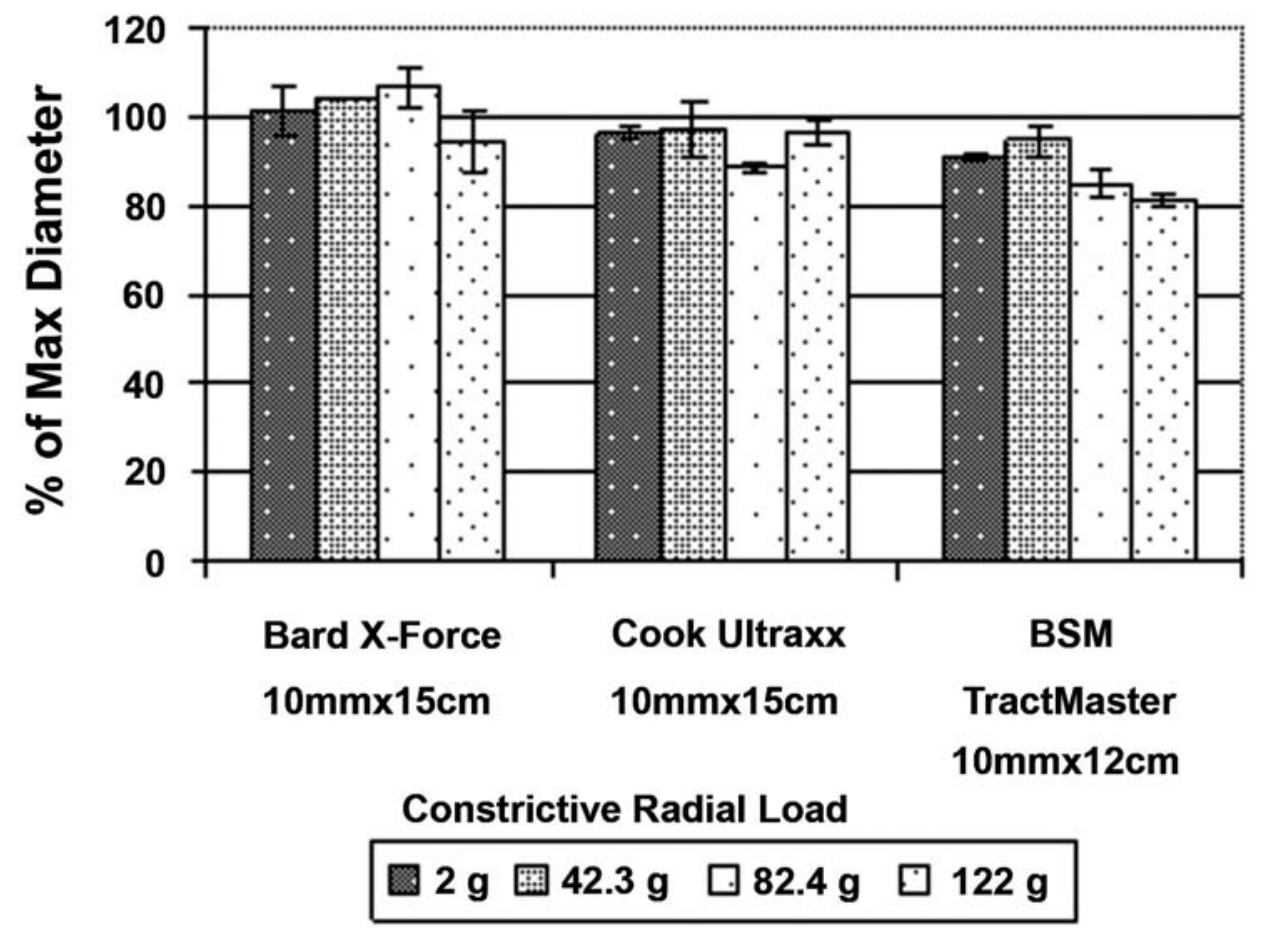

Figure 4 - Balloon dilation at burst pressure.

All balloons performed well under low constriction forces and reached at least $80 \%$ of the expected diameter by 10 ATM under all constrictive loads. Overall, the $95 \%$ confidence intervals for each pressure over all loads were not significantly different (Table-3). The ANOVA comparisons between the 3 balloons for each pressure and load were not statistically significant (Table-2). When compared to the anticipated inflated balloon diameter as stated per the manufacturer, all balloons performed radial dilation notably less than expected for all constrictive loads at low pressure, 4 ATM, $p<0.02$. However, radial dila-

Table 2 - Average coefficient of variance (CV,\%) at 4 ATM, 10 ATM and burst pressure for each constrictive load and ANOVA comparisons.

Coefficient of Variance $(\%)$

\begin{tabular}{|c|c|c|c|c|c|c|c|c|c|c|c|c|}
\hline \multirow[b]{2}{*}{ Balloon } & \multicolumn{4}{|c|}{4 АТМ } & \multicolumn{4}{|c|}{10 ATM } & \multicolumn{4}{|c|}{ Burst Pressure } \\
\hline & $2 \mathrm{~g}$ & $42.3 \mathrm{~g}$ & $82.3 \mathrm{~g}$ & $122 \mathrm{~g}$ & $2 \mathrm{~g}$ & $42.3 \mathrm{~g}$ & $82.3 \mathrm{~g}$ & $122 \mathrm{~g}$ & $2 \mathrm{~g}$ & $42.3 \mathrm{~g}$ & $82.3 \mathrm{~g}$ & $122 \mathrm{~g}$ \\
\hline $\begin{array}{l}\text { Bard X-Force } \\
10 \mathrm{~mm} \times 15 \mathrm{~cm}\end{array}$ & 8.40 & 4.45 & 4.39 & 1.12 & 0.80 & 4.12 & 4.40 & 8.58 & 5.60 & 0.00 & 4.37 & 7.13 \\
\hline $\begin{array}{l}\text { Cook Ultraxx }{ }^{\mathrm{TM}} \\
10 \mathrm{~mm} \times 15 \mathrm{~cm}\end{array}$ & 0.50 & 6.89 & 0.58 & 4.75 & 2.40 & 3.69 & 6.34 & 2.13 & 1.50 & 6.30 & 1.39 & 3.03 \\
\hline $\begin{array}{l}\text { BSM TractMaster }{ }^{\mathrm{TM}} \\
10 \mathrm{~mm} \times 12 \mathrm{~cm}\end{array}$ & 0.90 & 1.97 & 5.32 & 4.77 & 2.10 & 3.11 & 10.19 & 3.19 & 0.90 & 3.24 & 3.84 & 1.52 \\
\hline $\begin{array}{l}\text { ANOVA } \\
\text { ( } \mathrm{p} \text { Value) }\end{array}$ & 0.70 & 0.67 & 0.95 & 0.95 & 0.94 & 0.85 & 0.68 & 0.59 & 0.85 & 0.82 & 0.97 & 0.91 \\
\hline
\end{tabular}


Radial Dilation of Nephrostomy Balloons

Table 3 - Average 95\% confidence intervals for each pressure across all loads.

\begin{tabular}{|c|c|c|}
\hline \multicolumn{3}{|c|}{ 95\% Confidence Intervals } \\
\hline 4 ATM & Average Lower & Average Upper \\
\hline Bard X-Force $\mathrm{TM} 10 \mathrm{~mm} \times 15 \mathrm{~cm}$ & 78.1 & 104.3 \\
\hline Cook Ultraxx $\mathrm{x}^{\mathrm{TM}} 10 \mathrm{~mm} \times 15 \mathrm{~cm}$ & 78.8 & 95.9 \\
\hline BSM TractMaster ${ }^{\mathrm{TM}} 10 \mathrm{~mm} \times 12 \mathrm{~cm}$ & 72.3 & 87.4 \\
\hline 10 ATM & Average Lower & Average Upper \\
\hline Bard X-Force ${ }^{\mathrm{TM}} 10 \mathrm{~mm} \times 15 \mathrm{~cm}$ & 83.5 & 108.5 \\
\hline Cook Ultraxx ${ }^{\mathrm{TM}} 10 \mathrm{~mm} \times 15 \mathrm{~cm}$ & 81.8 & 102.3 \\
\hline BSM TractMaster ${ }^{\mathrm{TM}} 10 \mathrm{~mm} \times 12 \mathrm{~cm}$ & 77.0 & 101.4 \\
\hline Burst Pressure & Average Lower & Average Upper \\
\hline Bard X-Force ${ }^{\mathrm{TM}} 10 \mathrm{~mm} \times 15 \mathrm{~cm}$ & 89.5 & 115.7 \\
\hline Cook Ultraxx ${ }^{\mathrm{TM}} 10 \mathrm{~mm} \times 15 \mathrm{~cm}$ & 85.8 & 103.5 \\
\hline BSM TractMaster ${ }^{\mathrm{TM}} 10 \mathrm{~mm} \times 12 \mathrm{~cm}$ & 81.7 & 94.4 \\
\hline
\end{tabular}

tion was significantly closer to the projected inflated balloon diameter at 10 ATM under lower constrictive forces ( 2 and $42.3 \mathrm{~g}, \mathrm{p}>0.5$ ) but not for higher constrictive forces $(82.4-122 \mathrm{~g}, \mathrm{p}<0.04)$. All balloons were best able to reach the expected inflated balloon diameter for all constrictive forces at burst pressure, $\mathrm{p}>0.05$.

\section{COMMENTS}

The ability to obtain optimal percutaneous access is critical with respect to percutaneous nephrolithotomy (PCNL)-related complications including blood loss. Overall, technical success rates have been shown to be higher with fewer complications when access is obtained by a urologist versus an interventional radiologist (6). In particular, loss of tract access and pelviocalyceal tears can lead to excessive bleeding and blood transfusion. While most PCNL-related bleeding can be managed conservatively, up to $6 \%$ of patients require a blood transfusion (6).

Clinical and animal studies have shown similar blood loss, renal damage, and chronic renal function changes when comparing Amplatz and balloon dilation systems under a single puncture setting $(2,7)$. Moreover, histological similarities between the acute and chronic effects on the renal parenchyma suggest that the choice of dilatation can be based on physician preference (8). However, each method has potential benefits. Balloon systems can be accurately placed minimizing the risk of creating a false passage, are quick to use, and provide compressive hemostasis $(2,3,7-10)$. Balloon dilation is considered to be the safest method of percutaneous tract dilation with proper placement and use $(1-3,7,11)$. Radial dilation results in less renal movement away from the surgeon compared to longitudinal shearing forces as seen with other methods of track dilation. In addition, the minimization of tissue trauma and the pressure tamponade effect of the balloon may decrease blood loss.

However, balloon dilation is not able to create sufficient renal access in all patients. Joel et al. found balloon failure to occur in $17 \%$ of patients overall, including a $25 \%$ risk of failure in patients with a history of prior renal surgery compared to $8 \%$ of patients with no prior history (12). In addition, stone burden, patient body mass index (BMI), and history of pyelonephritis were not shown to be predictors for balloon failure (12).

Manual balloon inflation allows for controlled incremental changes in pressure; yet, this does not correlate with proportional changes in balloon diameter as we have shown in our study. Pressures of 4 to 5 ATM are typically sufficient to dilate a nephrostomy tract in patients with no prior renal surgery while higher pressures are necessary 
to achieve full dilation in those with a history of renal surgery due to retroperitoneal scar tissue (13). During balloon inflation, a characteristic "waist" will appear in areas of high resistance such as the renal capsule or a previous operative scar (14). The amount of force required to eliminate the waist will vary according to the degree of resistance and must exceed the resistance according to Newton's second law. Even so, this limiting force threshold may not be obtainable at full inflation. The uniaxial nature of the applied force during balloon inflation maximizes the net force in the direction of radial dilation in comparison to other dilator systems where dispersion of forces limit effectiveness under the same net force and are also subject to a friction force, or drag.

In this situation of significant perirenal or renal fibrosis or scarring, Metal Alken dilators and fascial dilators tend to be more effective than high pressure balloons (13-15). It is feasible that the newly developed balloon dilators with a burst pressure of 30 ATM may be successful in these situations. Other potential downsides to using balloon dilation include high cost, fixed length, and lack of effectiveness in the face of dysmorphic body habitus or severe fibrosis (14).

During our previous years of experience with the Boston Scientific Trackmaster ${ }^{\mathrm{TM}}$ we had noted that in approximately $5-10 \%$ of procedures, we would need to convert to use of an Amplatz dilator set due to persistent waisting of the balloon after full-inflation. Since completing this study, we have successfully performed 60 PCNL procedures with the use of the Bard X-Force ${ }^{\mathrm{TM}}$ without any failures.

\section{CONCLUSIONS}

From the individual percutaneous balloons tested, the Bard X-Force ${ }^{\mathrm{TM}}$ and Cook Ultraxx ${ }^{\mathrm{TM}}$ percutaneous balloons were found to be superior to the Boston Scientific Amplatz Tractmaster ${ }^{\mathrm{TM}}$ balloon with regards to radial dilation consistently closer to the expected diameter of the inflated balloon and better able to achieve reliable radial dilation against large constrictive forces simulating fascial or retroperitoneal scar tissue. However we note that intra-balloon variation in performance was not tested in this study. In vitro testing such as this may help select the appropriate clinical tool.

\section{CONFLICT OF INTEREST}

None declared.

\section{REFERENCES}

1. Davidoff R, Bellman GC: Influence of technique of percutaneous tract creation on incidence of renal hemorrhage. J Urol. 1997; 157: 1229-31.

2. Kukreja R, Desai M, Patel S, Bapat S, Desai M: Factors affecting blood loss during percutaneous nephrolithotomy: prospective study. J Endourol. 2004; 18: 715-22.

3. Safak M, Gögüş C, Soygür T: Nephrostomy tract dilation using a balloon dilator in percutaneous renal surgery: experience with 95 cases and comparison with the fascial dilator system. Urol Int. 2003; 71: 382-4.

4. Goharderakhshan RZ, Schwartz BF, Rudnick DM, Irby PB, Stoller ML: Radially expanding single-step nephrostomy tract dilator. Urology. 2001; 58: 693-6.

5. Hendlin K, Lund B, Dockendorf K, Ramani A, Monga M: Radial dilation of ureteral balloons: comparative in vitro analysis. J Endourol. 2005; 19: 575-8.

6. Lashley DB, Fuchs EF: Urologist-acquired renal access for percutaneous renal surgery. Urology. 1998; 51: 927-31.

7. Clayman RV, Elbers J, Miller RP, Williamson J, McKeel D, Wassynger W: Percutaneous nephrostomy: assessment of renal damage associated with semi-rigid (24F) and balloon (36F) dilation. J Urol. 1987; 138: 203-6.

8. Al-Kandari AM, Jabbour M, Anderson A, Shokeir AA, Smith AD: Comparative study of degree of renal trauma between Amplatz sequential fascial dilation and balloon dilation during percutaneous renal surgery in an animal model. Urology. 2007; 69: 586-9.

9. Stoller ML, Wolf JS Jr, St Lezin MA: Estimated blood loss and transfusion rates associated with percutaneous nephrolithotomy. J Urol. 1994; 152: 1977-81.

10. Roth RA, Beckmann CF: Complications of extracorporeal shock-wave lithotripsy and percutaneous nephrolithotomy. Urol Clin North Am. 1988; 15: 155-66.

11. Zagoria RJ, Dyer RB: Do's and don't's of percutaneous nephrostomy. Acad Radiol. 1999; 6: 370-7. 
12. Joel AB, Rubenstein JN, Hsieh MH, Chi T, Meng MV, Stoller ML: Failed percutaneous balloon dilation for renal access: incidence and risk factors. Urology. 2005; 66: 29-32.

13. McDougall EM, Liatsikos EN, Dinlenc CZ, Smith AD: Percutaneous Approaches to the Upper Urinary Tract. In: Alan M, Retik B, Darracott Vaughan JE, Wein J (ed.), Campell's Urology, 8th ed, Vol. 4. Philadelphia, WB Saunders. 2002; pp. 3320-60.
14. Press SM, Smith AD: Dilation of the Nephrostomy Tract: Use of Plastic Malleable Dilators - Amplatz System. In: Smith AD (ed.), Controversies in Endourology. Philadelphia, Pennsylvania. 1995; pp. 51-9.

15. Miller NL, Matlaga BR, Lingeman JE: Techniques for fluoroscopic percutaneous renal access. J Urol. 2007; 178: $15-23$.
Accepted after revision:

June 3, 2008

\author{
Correspondence address: \\ Dr. Manoj Monga \\ Department of Urology, University of Minnesota \\ 420 Delaware St. SE, MMC, 394 \\ Minneapolis, MN, 55455-0392, USA \\ Fax: + 1612 624-4430 \\ E-mail: endourol@yahoo.com
}

\section{EDITORIAL COMMENT}

The authors compare the characteristics of three balloon dilators used to achieve tract dilation in percutaneous nephrostolithotomy from three different manufacturers. An elegant experimental model was used to check the variation in balloon circumference with different pressures against constrictive loads that simulated fascial resistance. It has been extensively shown that balloon fascial dilation is less time consuming and results in less renal parenchyma damage and bleeding when compared to mechanical dilators (e.g. Amplatz and Alken dilators) $(1,2)$. Disadvantages include high cost, failure in performing access in obese patients and in those who have undergone previous open or percutaneous stone removal. In this study all of the balloon dilators were unable to reach $90 \%$ of their expected diameters with larger constrictive loads at low (4 ATM) and nominal (10 ATM) inflation pressures and two of them reached $90 \%$ of the expected diameter at their burst pressure. This interesting finding corroborates the idea that urologists may select a balloon with a higher pressure rating when treating multi-operated patients. Unfortunately balloons are expensive and a $25 \%$ failure rate to create adequate renal access in patients with a history of prior renal surgery has been reported (3); probably in such cases using mechanical dilators can be more cost effective especially in developing countries.

\section{REFERENCES}

1. Traxer O, Smith TG 3rd, Pearle MS, Corwin TS, Saboorian H, Cadeddu JA: Renal parenchymal injury after standard and mini percutaneous nephrostolithotomy. J Urol. 2001; 165: 1693-5.

2. Davidoff R, Bellman GC: Influence of technique of percutaneous tract creation on incidence of renal hemorrhage. J Urol. 1997; 157: 1229-31.

3. Joel AB, Rubenstein JN, Hsieh MH, Chi T, Meng MV, Stoller ML: Failed percutaneous balloon dilation for renal access: incidence and risk factors. Urology. 2005; 66: 29-32.

\author{
Dr. Eduardo Mazzucchi \\ Division of Urology \\ University of Sao Paulo, USP \\ Sao Paulo, SP, Brazil \\ E-mail:mazuchi@terra.com.br
}




\section{EDITORIAL COMMENT}

Choice of nephrostomy tract dilation technique is significant in minimizing the risk of complications such as blood loss and perforation of the collecting system.

Among other choices, Balloon systems have typically been the instrument of choice for many surgeons as they allow for one-step dilation, minimized total operative and fluoroscopic time and reduced risk of hemorrhage in comparison to other methods of tract dilation. It has been proposed that the lateral compressive forces produced by the balloons are less traumatic and thereby minimize complications in comparison to the angular shearing forces exerted by successive dilation methods (1).

The potential downsides to using balloon dilation include high cost, fixed length, and lack of or severe fibrosis (2).

The ideal site of percutaneous puncture should be selected to maximize the use of rigid instruments, minimize the risk of complications and obtain stone-free status. effectiveness in the face of dysmorphic body habitus

This study compares the ability of several percutaneous balloons to expand under different radial constrictive forces.

All balloons were unable to reach $90 \%$ of their expected diameter with larger constrictive loads (122g) at low (4 ATM) and nominal (10 ATM) inflation pressures. Balloon systems can be accurately placed minimizing the risk of creating a false passage, are quick to use and provide constant hemostasis.

\section{REFERENCES}

1. Miller NL, Matlaga BR, Lingeman JE: Techniques for fluoroscopic percutaneous renal access. J Urol. 2007; 178: 15-23.

2. Al-Kandari AM, Jabbour M, Anderson A, Shokeir AA, Smith AD: Comparative study of degree of renal trauma between Amplatz sequential fascial dilation and balloon dilation during percutaneous renal surgery in an animal model. Urology. 2007; 69: 586-9.

Dr. Mauricio Rubinstein Division of Urology

Federal University of Rio Janeiro State, UNIRIO Rio de Janeiro, RJ, Brazil E-mail:mrubins74@hotmail.com

smoothly introduction of the Amplatz sheet over it to the urinary tract.

It becomes expensive and extremely undesir-

The balloon dilation used in percutaneous access for kidney surgery represents a very effective method for accessing the urinary tract. It is faster and less traumatic than other kinds of dilators as discussed by the authors. However, some details might be considered like: 1 . It is necessary to have some space in the urinary tract for the tip of the balloon dilator, in order to dilate all the way from the skin to the urinary tract; 2 . The accessed calyx should be a posterior one, otherwise during the dilation the balloon becomes straight and could leave the calyx; 3 . The balloon should be dilated uniformly to permit the able when an irregularity of the balloon occurs (as a figure eight) which will not permit the introduction of the Amplatz sheet. It generally happens by muscle fascia or fibrous tissue resistance around the balloon. Then, the urologist has to dispose off his balloon dilator and use another kind. This paper accurately analyses the third condition above with practical application for surgeons at the moment of choosing the dilator in a percutaneous surgery. It is of great importance to choose the reliable dilators that will accomplish their task. It can also be considered as 
an appeal for producers in order to improve their products. However, we may question if only three dilators of each brand represent a true performance profile. Additionally, there are other not considered aspects of each product that may have an influence on the preference of the surgeon.

Dr. Anuar Ibrahim Mitre Division of Urology University of Sao Paulo, USP Sao Paulo, SP, Brazil E-mail:anuar@mitre.com.br

\section{EDITORIAL COMMENT}

Percutaneous surgery has firmed its place as gold standard treatment for large and/or complex kidney stones; and access to the collecting system is the key-factor for a successful and safe procedure.

The present manuscript translates the unlimited benefits of coupling medicine with engineering in optimizing surgical instruments, medical tools and consequently surgical procedures. The University of Minnesota's urology team has great experience in testing endourological devices and has granted the medical literature with another interesting and useful manuscript.

Dilating balloon catheters have met with the acceptance of urologists as they save time and simplify the percutaneous surgery. The authors have compared the performance of different brands of dilating balloons in artificially reproduced case scenarios. Interestingly, devices showed different performances on similar testing settings and it was even more significant at higher compressive forces (simulating a stricture for example). This information is of particular importance for endourologists who depend on the efficiency of instruments to successfully treat a patient.

Another message one can take from the study is that one should anticipate the difficulties of a procedure and choose the right tool to deal with them.

Body mass index (BMI) could be another indication for nephrostomy balloons.

Dr. Renato N Pedro \& Dr. Nelson Rodrigues Netto Jr. University of Campinas, Unicamp Campinas, Sao Paulo, Brazil E-mail:nrnetto@uol.com.br 